\title{
Passado histórico, presente historiográfico: considerações sobre "História e Estrutura" de Michel de Certeau*
}

\author{
Historical past, historiographical present: notes on Michel de Certeau' \\ "Histoire et Structure"
}

\author{
João Rodolfo Munhoz Ohara \\ ohara.hal@gmail.com \\ Doutorando \\ Universidade Estadual Paulista "Júlio de Mesquita Filho" - Assis \\ R. Delaine Negro, 50/105-C \\ 86055-680 - Londrina - PR \\ Brasil
}

\begin{abstract}
Resumo
No ensaio "História e Estrutura", Michel de Certeau pensa o ofício do historiador como um problema, um conjunto de procedimentos que merece uma análise cuidadosa. Nesse texto, Certeau discute a tensão colocada no enfrentamento com o Outro, no instante em que o historiador encontra a alteridade do que passou, e mais especificamente os efeitos do pensamento dito "estruturalista" sobre tal tensão. Pensamos que muitas das considerações de Certeau ainda são relevantes para refletir sobre a escrita da história e a relação dos homens com o tempo neste período que se diz de crise epistemológica. Assim, nosso trabalho busca explorar os apontamentos de Certeau e articulá-los ao que consideramos ser um projeto maior do autor, a saber, a crítica do fazer historiográfico enquanto prática, desenvolvida alhures.
\end{abstract}

\section{Palavras-chave}

Michel de Certeau; Historiografia; Escrita da história.

\begin{abstract}
Michel de Certeau's essay "Histoire et Structure" develops a reflection on the historian's practice, something that he takes as a problem that deserves a careful analysis. In this text, Certeau discusses the tension generated by the historian's confrontation with the otherness of past events. More specifically, he explores the effects of "structuralist" thought on such tension. This article takes Certeau's considerations on the issue as a still relevant base from which to think on both historical writing and the human experience of time. It will explore Certeau's insights and place them in relation a broader project of his, namely the criticism of historiographical practice.
\end{abstract}

\section{Keywords}

Michel de Certeau; Historiography; Writing of history.

Enviado em: 16/7/2012

Aprovado em: 16/11/2012

\footnotetext{
* Este artigo contou com o apoio da Coordenação de Aperfeiçoamento de Pessoal de Nível Superior.
} 
Michel de Certeau faz parte de uma geração de historiadores, principalmente franceses, que, em determinado momento, voltou-se para a própria prática do historiador de maneira crítica: o ofício não seria, para eles, um dado acabado, mas uma série de disposições e operações histórica e socialmente localizáveis, a partir das quais se constituiria a disciplina tal como a conhecemos. É conhecida a fórmula tripartite que Certeau elaborou em A escrita da história: a historiografia seria a articulação entre um lugar, uma prática e uma escrita. A partir de tal concepção é possível pensar a nossa prática como uma atividade a ser problematizada, ao invés de ocultada pelas linhas escritas pelo pesquisador. Mas para ele a reflexão teórica em história tem um lugar preciso: ela

[...] é pertinente quando a prática histórica torna-se o lugar de um questionamento; caso contrário, teríamos uma problemática do tipo ideológico, uma forma de sonho desvinculado das questões que, efetivamente, se formulam no decorrer de um procedimento científico na área de história (CERTEAU 2011, p. 163).

Deter-me-ei por um instante nesta citação. Tomar a prática histórica como lugar de um questionamento, como já disse, implica em desnaturalizar aquilo que nós, historiadores, fazemos. Trata-se de tirar desses procedimentos o estatuto meramente técnico e de reintroduzi-los na lógica da historicidade, e assim pensá-los como produtos de um campo profissional delimitado. Para Certeau, então, as questões levantadas por esse tipo de epistemologia da história deve, necessariamente, ter como fundamento e referência a prática efetiva da história ${ }^{1}$. Isso responde principalmente à objeção - ainda muito comum - de grandes historiadores aos mares nebulosos e abstratos da epistemologia filosófica: mesmo quando trabalha com abstrações, o historiador que se dedica a pensar a sua prática deveria então ter sempre como objetivo pensar as suas situações reais de trabalho, e não os problemas clássicos da filosofia. Distanciar-se por demais do lugar social demarcado para os historiadores seria arriscar-se a se perder no "sonho ideológico".

O procedimento científico citado se refere ao conceito bastante particular de ciência que encontramos em Certeau: o científico trata da "[...] possibilidade de estabelecer um conjunto de regras que permitam "controlar" operações destinadas à produção de objetos determinados" (CERTEAU 2008, p. 109, grifo do autor). Esse é um conceito que traz em si, mas apenas implicitamente, algumas questões que são bem claras para Certeau, como o problema da referência ao real ou das condições da verdade em história. Sem ceder ao ceticismo pós-moderno - se é que se pode falar de um pós-modernismo - ele traça o problema da referencialidade a partir de um flerte com a psicanálise freudiana e lacaniana, fundamentando seu conceito de ciência sobre noções bem claras de historicidade do saber e do problema das relações entre o discurso e seu outro, o real. Assim, tais regras estão sempre colocadas na tensão tripartite da

\footnotetext{
${ }^{1}$ Frank Ankersmit também declara que a reflexão filosófica sobre a escrita da história deve tomar por referência aquilo que o historiador efetivamente faz, e "[...] evitar tentar conduzir a escrita da história em uma direção ou outra" (ANKERSMIT 2012, p. 325).
} 
operação historiográfica, e não pretendem funcionar como leis universais. ${ }^{2}$ Eis que Certeau propõe, então, pensar tais procedimentos a partir da sua própria prática: a história religiosa do século XVII. Deter-me-ei, portanto, no texto "História e Estrutura", parte do livro História e psicanálise: entre ciência e ficção (2011 [1987; 2002]), para uma análise precisa e cuidadosa dos elementos pertinentes; eventuais diálogos desse texto com A escrita da história (2008 [1975]) serão inevitáveis, mas não estão no foco principal do presente texto. ${ }^{3}$

\section{No início, um mundo imaginado}

Para Certeau, todo trabalho historiográfico começa a partir de uma ideia bastante particular acerca do passado e daqueles sobre os quais o pesquisador direcionará sua atenção. O início da prática é análogo ao trabalho do crocheteur: ${ }^{4}$ "[...] ele transforma essas coisas [os objetos descartados], dependurados na ponta de seu gancho, no sonho da casa que ele nunca chegará a entrar; ou no sonho de refeições e de intimidades que ele nunca chegará a conhecer" (CERTEAU 2011, p. 164). Lembremos aqui que em "A Operação Historiográfica" Certeau diz que todo trabalho histórico "[...] começa com o gesto de separar, de reunir, de transformar em "documentos" certos objetos distribuídos de outra maneira" (CERTEAU 2008, p. 81, grifo do autor). Essa catança, gesto constitutivo da historiografia, procede pinçando elementos dispersos no plano da experiência e organizando-os segundo um critério imaginado pelo historiador: trata-se de ordenar o heterogêneo ${ }^{5}$, mais efetivamente, encontrar o Outro apenas no plano da imaginação - portanto, sem sair do território do Mesmo. Mas o historiador não pode parar aí: após a separação dos materiais é preciso investigá-los, questioná-los, problematizá-los. A historiografia francesa do século $X X$ formulou essa questão muito habilmente: as fontes, eternos ancoradouros do historiador, não falam por si; é preciso que o historiador as questione, as interrogue, formule problemas para que possa retirar dali o material efetivo de sua narrativa.

Nesse processo de avaliação das fontes, aos poucos o historiador percebe o processo sem volta do afastamento desse Outro: "Desse momento, escalonado incessantemente no tempo, é que data o nascimento do historiador; essa ausência é que constitui o discurso histórico" (CERTEAU 2011, p. 164, grifo do autor). Ora, o passado vai se mostrando irredutível à imaginação do historiador;

\footnotetext{
${ }^{2}$ Neste sentido, discordo da interpretação de Roger Chartier, segundo quem "tais critérios de validação não são ligados a uma instituição específica. Eles não são nem etnicamente fundados nem orientados pelo gênero" (CHARTIER 1998, p. 256). Penso que o mérito da perspectiva de Certeau reside justamente no oposto, isto é, na historicidade dos critérios de validação do saber e das relações de poder intrínsecas ao lugar social de produção. Portanto, compartilho da leitura de TERDIMAN 1992, TERDIMAN 2001 e WANDEL 2000.

${ }^{3}$ Elaboro em outro texto a leitura comparativa de textos publicados em mais de uma versão por Certeau (como a "Operação Histórica" e a "Operação Historiográfica", por exemplo, entre outros textos das coletâneas História e psicanálise e Heterologies). Recuso, portanto, considerar o pensamento de Certeau como um todo fechado; é preciso pensar também nos caminhos abandonados, nas noções tornadas mais precisas, na emergência de novas temáticas.

${ }^{4}$ Tipo de catador de rua que usa um gancho (crochet) para separar e pegar os objetos das lixeiras.

${ }^{5}$ Embora Paul Ricoeur argumente habilidosamente que a experiência não é totalmente heterogênea, penso que a ideia em questão - tanto no ordenamento inicial dos materiais quanto na captura final da alteridade na produção do texto historiográfico - diz respeito a uma vontade de homogeneizar o heterogêneo. Foge de nosso escopo, no entanto, discutir a hermenêutica dessa vontade. Para mais, cf. RICOEUR 2010.
} 
aquele mundo sonhado encontra a resistência de vozes dispersas e heterogêneas - e perceber esse afastamento despedaça a ilusão de homogeneidade de que se munia o olhar sonhador. A alteridade postulada socialmente pelo corte entre presente e passado se impõe ao historiador por essa diferença irredutível:

A "ressurreição" do passado consiste em elaborá-lo de acordo com nosso desejo. Ora, tal operação revelava-se impossível. De fato, esses cristãos do século XVII tornavam-se, para mim, estrangeiros: não graças ao que eu conhecia a seu respeito, mas ao que eu me apercebia de minha própria ignorância e da sua resistência (CERTEAU 2011, p. 165, grifo do autor).

O passado não se curva à vontade imperiosa e colonizadora do historiador. A diferença antes postulada agora se apresenta de fato: encontramos aquilo que não somos, aquilo que foi, e é nesse instante que cruzamos a fronteira entre o Mesmo e o Outro. À diferença postulada, o historiador responde imaginando; à diferença de fato, ele responde avançando sobre esse espaço desconhecido, que resiste à vontade de compreendê-lo. ${ }^{6}$ Essa vontade colonizadora e imperiosa é sempre colocada em analogia com o avanço colonialista europeu no período moderno: a linguagem do presente avança sobre o material - ele também presente, mas que traz valores que remetem ao passado - e lhe impõe uma lógica determinada. E para explicar essa diferença Certeau encontra pela primeira vez no texto o conceito de estrutura:

Tal operação me ensinava, e nos ensina - a nós, historiadores - que existe, oculto em tal passado, certa estruturação que nos oferece resistência; e, por outro lado, oculto em meus preconceitos ou nas nossas intenções presentes, um tipo de estruturação que determinava o primeiro olhar da curiosidade focalizada neles (CERTEAU 2011, p. 165-166, grifo do autor).

Podemos perceber que a estruturação evocada é dupla: não é exclusividade de um passado retomado, estranho, sobre o qual a luz da racionalidade presente atuaria iluminando suas ignorâncias. Certeau percebe que também nós estamos estruturados, e é só em função dessa estruturação que nossa curiosidade - o olhar sonhador - se volta para esse passado. É esse choque de estruturas que indica a falha no lugar que o historiador imaginava uma continuidade: o choque da singularidade daquilo que foi e não é mais.

Tal colocação nos permite uma pausa: há quem objete a tal perspectiva o fato de que hoje é possível pensar uma história do presente, ou história imediata, operacionalizando a crítica do historiador a acontecimentos presentes, e, portanto, as colocações de Certeau estariam superadas. Essa objeção pode ser atacada por duas frentes: em primeiro lugar, remeter-me-ei à concepção de tempo como "triplo presente" de Agostinho tal como analisada por Paul Ricoeur para argumentar que tal objeção dá ao presente uma extensão que não resiste à prova; em segundo lugar, retomarei François Hartog e seu conceito de

\footnotetext{
${ }^{6}$ A compreensão em Certeau remete sempre a um jogo entre dois sentidos: entender o Outro (o papel da empatia na compreensão, Verstehen) e também cercá-lo no esforço para reconduzir essa alteridade à mesmidade, homogeneizando a experiência tão diversa ao inscrevê-la na estrutura do texto.
} 
regime de historicidade para lembrar que a capacidade de historiar e historicizar determinado período em determinado sentido é também histórica - ou seja, capaz de se reconfigurar ao longo dos tempos e das sociedades.

\section{Condições de possibilidade de uma história do presente}

Primeiramente, o tempo "triplo": Agostinho dedica parte de suas Confissões ao problema do tempo em dimensão distinta do tempo físico de Aristóteles; trata de pensar o tempo humano a partir do enfrentamento do argumento cético do tempo como não-ser: ${ }^{7}$ o passado não é mais, o futuro não é ainda e o presente não permanece. Para Agostinho, após depurar o problema, pode-se pensar o tempo em relação à intentio e à distentio animi; tal concepção presume a ideia do triplo presente. Que seria isso? Para ele, o passado e o futuro só se apresentam ao homem como memória e expectativa, respectivamente; isso significa dizer que pode-se falar de um presente do passado (a memória e os vestígios), um presente do presente (a attentio, ou a "visão") e um presente do futuro (a expectativa). Essa ideia, no entanto, aponta para a percepção de que, embora futuro e passado só existam de maneira presente, esse próprio presente é efeito da passagem do futuro para o passado: o presente, "[...] na medida em que passa, reduz-se a um ponto (in puncto praeterit): é a expressão mais extrema da ausência de extensão do presente. [...]" (RICOEUR 2010 , p. 36-37, grifo do autor). O presente como aquilo que passa: eis que a "história do presente" é apenas a história de um passado mais próximo. Se esse passado próximo pode fugir, mesmo que apenas parcialmente, à alteridade intransponível de que fala Certeau, ao mesmo tempo o historiador pode se valer da diferença de que se mune o etnólogo: a relação com o Outro continua partindo de uma falha entre ele e o Mesmo, apenas objetivando um grupo mais ou menos relativamente contemporâneo.

Em segundo lugar, a reflexão de Hartog a respeito dos regimes de historicidade nos permite perceber a historicidade própria às modalidades de história atentas ao passado mais próximo (tomado como presente). Assim define Hartog:

\footnotetext{
"Regime de historicidade", escrevíamos então, podia se compreender de duas formas. Em uma acepção restrita, é como uma sociedade trata seu passado. Em uma acepção ampla, regime de historicidade serviria para designar "a modalidade de consciência de si de uma comunidade humana". [...] Mais precisamente, a noção devia poder fornecer um instrumento para comparar tipos de histórias diferentes, mas também e mesmo antes, eu acrescentaria agora, para iluminar modos de relação ao tempo: formas de experiência do tempo, aqui e lá, ontem e hoje. Maneiras de ser no tempo (HARTOG 2006, p. 263, grifo do autor).
}

A ideia trata então de como cada sociedade se compreende e compreende os outros como dotadas de historicidade. Citá-la me serve aqui para dizer: a

\footnotetext{
7 Não tomarei a discussão em sua totalidade para evitar fugir por demais do tema principal deste trabalho. Para acompanhá-la na íntegra, ver RICOEUR 2010, p. 13-55.
} 
"história do presente" se trata apenas de um sintoma de um novo regime de historicidade (chamado por Hartog de presentista) configurado atualmente que permite que uma sociedade se enxergue historicamente em sua experiência presente. Ora, os mecanismos de produção da história não escapam, dessa maneira, à lógica pensada por Certeau: o corte imposto entre passado e presente e a produção da alteridade apenas passam a operar em uma margem mais próxima do presente-passagem, retomando Agostinho e Ricoeur. Outros sintomas podem ser listados, ainda segundo Hartog: a febre de patrimonialização, as políticas da memória, a força crescente de movimentos sociais buscando direitos de minorias historicamente marginalizadas, por exemplo.

\section{Fazer história, produzir a diferença}

Retorno, então, ao texto de Certeau. Eis que perceber a falha entre o presente e o passado e se dar conta de que essa alteridade escapa aos juízos e aos sonhos do historiador não se trata de uma percepção dada, objetiva: ela é a própria instituição da historiografia na medida em que percebe que até mesmo as continuidades estão trespassadas por rupturas de significação das práticas.

[...] em vez de corresponder ao objetivo fixado no começo de minha pesquisa, o passado é bem mais diferente do que eu havia julgado, ao empreender a busca de estrangeiros semelhantes a mim. [...] "Faço história" no sentido em que não só produzo textos historiográficos, mas tenho acesso, por meu trabalho, à consciência de que algo se passou, atualmente morto, inacessível como vivo. A estrutura defende e exprime esta aquisição da experiência histórica; ela diz que houve algo diferente (CERTEAU 2011, p. 166-167, grifo do autor).

Esta citação nos coloca alguns problemas: de que trata a "consciência" evocada por Certeau? E como a estrutura, conceito tão usado para indicar as grandes continuidades históricas, pode dizer algo sobre as rupturas entre passado e presente? Em primeiro lugar, a consciência acessada pelo historiador não coincide com a consciência do passado em si: trata-se de uma consciência de que há um passado, e de que ele está morto. Não significa dizer que o historiador consegue operar como era a ambição de Michelet e "dar voz" aos mortos; essas vozes emanando dos túmulos do passado podem, sim, falar ao historiador, mas é sempre este quem as reintroduzirá no pensável do presente. Afirma Richard Terdiman:

A heterologia busca dar crédito total à diversidade [otherness] da alteridade [alterity] - à sua capacidade de não ser simplesmente um efeito mistificado do sistema e do discurso próprios do observador. O problema, tanto para nossa teoria quanto para nossa prática, é ver como imaginar um circuito de comunicação entre entidades autenticamente diferentes, um circuito verdadeiramente bilateral e bidirecional (TERDIMAN 1992, p. 7, grifo do autor).

Penso que o problema talvez não seja tratável para a historiografia na estrutura narrativa convencional contemporânea, ou, mesmo que seja, não 
estou certo que o resultado seria um texto inteligível. Como Certeau sempre enfatizou, o Outro de que o historiador fala está morto - não no sentido de que não tem qualquer relevância para o mundo dos vivos, mas precisamente que já não pode se pronunciar por si próprio. Em um flerte claro com a psicanálise, ele diz que a historiografia trata dos mortos para dar lugar aos vivos; o objetivo é claro: trata-se de sepultar o morto a fim de evitar que seu fantasma tenha efeitos destrutivos sobre os vivos (CERTEAU 2008, p. 57, 95, 107, 108). Assim, ainda que informado e impressionado pela experiência da alteridade, quem fala é sempre o historiador.

Em seguida, a estrutura nos informa sobre rupturas na medida em que aponta que os núcleos significativos que atravessam os tempos, as ditas continuidades, são continuamente refigurados pelas sociedades. Historicizando o exemplo clássico de Lévi-Strauss, se o incesto é um tabu perene, não significa dizer que ele é tratado da mesma maneira durante todo o tempo; mesmo os tabus sociais são tratados de acordo com lógicas particulares em cada grupo e em cada época. Essa busca pelas unidades atômicas da significação humana (os mitemas) com certeza apontam para certas perenidades; mas o que mais importa ao historiador é observar como essas unidades mínimas perenes são combinadas de maneiras diferentes, sempre históricas, ao longo dos tempos neste sentido, retomando a ideia de que a continuidade é sempre atravessada pela ruptura. Assim é que Certeau pode dizer de uma estrutura que ela expõe a diferença. Mas uma distinção se faz necessária:

No entanto, o essencial é, aqui, a articulação entre estes dois pontos: a ausência é, para o discurso histórico, a condição de possibilidade que ele desvela ao desdobrar-se; e a "estrutura" é a ferramenta conceitual que permite "compreender" e manifestar essa ausência (CERTEAU 2011, p. 167).

A ausência, portanto, não se confunde diretamente com a estrutura. Se a ausência é um fenômeno a priori, a condição de um discurso histórico, a estrutura só surge como ferramenta explicativa no presente historiográfico. Para Certeau, se a alteridade é a base sobre a qual se produzirá a compreensão pelo presente do passado, cada presente historiográfico será responsável pelo uso de um determinado conceito operacional para tratar dessa alteridade desvelada. Trata-se de produzir uma ideia a partir da qual se possa recortar no Outro determinada característica que possa ser usada como parâmetro comparativo - o que não significa em absoluto a produção de um discurso simplesmente comparativo. Essa "comparação" está sempre a serviço da compreensão, da reinscrição dessa alteridade no presente: o presente historiográfico pensa as estruturas do passado histórico porque pressupõe a existência de estruturas atuantes tanto em uma quanto em outra dimensão.

Quanto ao presente historiográfico, Philippe Carrard lembra bem: "O que eles [os historiadores] deveriam fazer concretamente para estabelecer sua ciência [awareness] de suas próprias retórica, política, ética, visão de história, e filiação social/institucional?" (CARRARD 2001, p. 478). Certeau não oferece a resposta a essa pergunta. Como coloquei anteriormente, é preciso, como 
o próprio Carrard se pergunta, pensar se uma narrativa que explicite tanto quanto necessárias suas condições de possibilidade seria de fato possível ou, se possível, se seria inteligível. É possível conjecturar se o trabalho reflexivo deveria acompanhar materialmente a narrativa, ou se ele é responsabilidade de um trabalho à parte; de qualquer forma, essa reflexividade que levou à formulação da tríade "lugar social/procedimentos de análise/escrita" permanece uma abordagem poderosa quanto à história da historiografia. ${ }^{8}$

Neste ponto devemos lembrar que, no período de produção desse texto segunda metade do século XX - o estruturalismo praticamente impunha-se como horizonte de diálogo e de enfrentamento no pensamento francês. As considerações críticas de Lévi-Strauss acerca da história seriam rebatidas por Braudel e os Annales, pela filosofia de Michel Foucault e por tantos outros pensadores que buscavam repensar a história à luz das colocações da antropologia estruturalista. Trata-se aqui de uma disputa clara de campos do conhecimento: à ideia de uma estrutura colocada fora do tempo (as tais unidades mínimas da significação humana buscadas pela antropologia estruturalista), responsável por explicar a perenidade de determinados temas ao longo do tempo e em sociedades tão apartadas quanto possível, a história responde dizendo que as estruturas são, apesar de tudo, históricas, e portanto suscetíveis aos efeitos do tempo e das reconfigurações operadas mais ou menos lentamente pelos homens em sociedade. A resposta mais clara e mais disseminada seria a das durações de Braudel, mas podemos ver que Certeau tem sua abordagem própria - fruto de seu diálogo peculiar com a obra de

204 Freud e de Lacan. Para ele, o corte estrutural é mais uma das fundações do saber historiográfico do que o fim almejado por ele, baseando-se na ideia da pesquisa como uma experiência de limites, do contato com uma alteridade irredutível. ${ }^{9}$

Eis então que o historiador se vê tensionado entre duas forças do presente historiográfico:

Paradoxalmente, ao desvelar uma descontinuidade, ele tem, ao mesmo tempo, o objetivo de dizê-la, relatá-la, analisá-la, explicá-la e, portanto, introduzi-la no texto homogêneo de uma cultura presente, no interior de uma literatura, com os instrumentos intelectuais da época em que se situa a narrativa historiográfica. Trabalho curioso: ele parece negar, pela obra realizada, a ruptura que ele faz aparecer (CERTEAU 2011, p. 168, grifo do autor).

Essa tensão, própria da atmosfera de luta entre um estruturalismo a-histórico e a posição do campo historiográfico daqueles anos, ainda perdura. De um extremo a outro, vemos a discussão em torno da ferramenta que seria

\footnotetext{
${ }^{8}$ Por isso, quando, explicando o "lugar social", Jacques Revel diz que "O historiador se submete aos imperativos de uma profissão pela qual deve se fazer conhecer e com a qual ele se encontra em negociação constante por tudo que toca suas maneiras de fazer e de dizer" (REVEL 2010, p. 145). Pode-se ver aqui não apenas o fundamento para historicizar a historiografia passada, mas a nossa própria historiografia presente. $O$ jogo entre o Outro e o Mesmo, quando da história da historiografia, sugere a possibilidade de pensar os limites de nossa própria prática.

${ }^{9} \mathrm{Em}$ texto de 2002, Peter Burke sugere que o tema da alteridade surge em Certeau a partir de suas leituras teológicas. Parece-me uma hipótese plausível. No entanto penso que é preciso atentar para o papel importante da alteridade na psicanálise, principalmente em sua vertente lacaniana, disciplina com a qual Certeau dialoga abundantemente.
} 
supostamente mais adequada para lidar com a Outro. Com efeito, o trabalho mais incisivo na dimensão de ruptura entre passado e presente ainda só pode se tornar pensável operando a partir de concepções presentes - uma estrutura textual e narrativa, uma concepção da história e um corpo delimitado de procedimentos, para listar apenas alguns aspectos. A tensão da compreensão se impõe absorvendo a diferença que desvelou, produziu e busca comunicar. Trata-se, como diz Certeau, de consequências da "experiência do limite": se já não podemos nos pensar como o todo, como podemos pensar, então, essa alteridade que se nos apresenta? É preciso avançar um passo e também se perguntar: é possível expressar essa alteridade na escrita de maneira que lhe faça justiça? O que seria essa justiça? E qual seria a forma dessa expressão ${ }^{10}$

\section{Momentos das ferramentas conceituais: cronologia (séculos XVI e XVII) e estrutura}

Certeau problematiza então a questão das ferramentas do historiador: aponta para como nos séculos XVI e XVII a necessidade de compreender o Novo Mundo e as viagens ao extremo oriente impôs ao pensamento europeu a criação de um parâmetro que permitisse tal tarefa. Fruto dessa experiência dos limites, essa compreensão da alteridade através de uma referência conceitual comum foi a resposta ao esfacelamento das certezas apoiadas sobre o conhecimento do mundo pelos antigos.

Um trabalho que tendia a restaurar o homogêneo, graças ao discurso de uma compreensão, organizou-se (estruturou-se) em função dessa ameaça de dissuasão interna; aliás, ele se operou segundo diversas modalidades. [...] Vou mencionar apenas um caso que se situa, também, no setor religioso: a cronologia. Para superar a distância que se criava entre o universo americano ou chinês e o mundo ocidental, foram recuadas a períodos mais antigos, as datas dos livros ou fatos do Antigo Testamento suscetíveis de oferecerem pontos iniciais comuns a filiações diferentes [...] (CERTEAU 2011, p. 169-170, grifo do autor).

Eis que no período em que as potências europeias saíram em viagens pelo mundo, tornou-se necessário pensar essas tradições que careciam de qualquer referência ao pensamento cristão. A partir do esforço de referir as Escrituras a uma cronologia mundana - ainda hoje uma questão que mobiliza certos grupos - a datação de uma maior antiguidade desses eventos se tornou a base comum a partir da qual se pôde pensar essa alteridade irredutível. Esses pensadores franceses cristãos dos séculos XVI e XVII constroem, então, suas reflexões ao redor desse aparato conceitual construído. Trata-se aqui do estabelecimento de certo modelo determinado a partir do qual um grupo é capaz de pensar aquilo que está além de suas fronteiras.

De maneira semelhante, o modelo estruturalista oferece, segundo Certeau, "um estatuto científico e um rigor ao que veio a ser, para nós, uma condição de 
possibilidade para o pensamento ou para o discurso [...]" (CERTEAU 2011, p. 171, grifo do autor). Esse "rigor científico" se referiria à possibilidade de encontrar nas estruturas sociais o fenômeno objetivo por excelência da experiência humana: o universal, o transcendente, aquilo que comporia ao menos parte da essência da vida social humana. Ele continua:

Talvez, no futuro, essa forma presente, estrutural, oferecida à possibilidade de pensar, venha a aparecer tão frágil quanto havia sido o recurso da historiografia "clássica" a um ponto de partida original e a uma cronologia que tinham permitido constituir, em uma série, as relações do Ocidente cristão com outras civilizações. De qualquer forma, subsiste o problema suscitado, aqui e lá, em termos diferentes [...] (CERTEAU 2011, p. 171-172).

Ora, explicita-se aqui a consciência de historicidade da prática historiográfica. Penso que é aqui que Certeau mostra mais claramente a peculiaridade do seu conceito de ciência: já não se trata do estabelecimento d'O Método, a partir do qual seria possível apreender e compreender o mundo, a alteridade, e instituir um saber tão objetivo quanto real. Para Certeau, a atenção para com a historicidade do discurso e as condições de possibilidade do estabelecimento de um saber são inseparáveis. É a atenção aos limites do contemporâneo que permitem estabelecer as "[...] regras que permitam "controlar" operações destinadas à produção de objetos determinados" (CERTEAU 2008, p. 109, grifo do autor): perceber que as regras, as operações e a produção de objetos são, como ele diz, determinadas - portanto, históricas - é se permitir pensar o saber histórico como um saber legítimo dentro de uma possibilidade da experiência. ${ }^{11}$ Assim, ao argumento cético da impossibilidade do saber, coloca-se a objeção clara de que mesmo que todo discurso seja histórico, ainda é possível elaborar um saber significativo para uma determinada sociedade em determinado tempo. Tal perspectiva é reforçada no fechamento de sua apresentação:

Para terminar, voltarei, de preferência, aos "espirituais" da época clássica,
selvagens do século XVII, limitando-me a dizer que sua ausência, talvez,
me ensinou a tornar-me um historiador, que o estudo desse tema obriga
a avaliar, no desenvolvimento de uma prática científica, a aventura e
os riscos implicados pela ingênua ambição de "compreender" e que,
por último, a modalidade "estruturalista" dessa compreensão abre, sob
uma forma particular (presente), o problema constante da relação entre
uma inteligibilidade e o que a torna possível. "História e estrutura":
esse título questiona a relação de qualquer discurso historiográfico com
suas condições de possibilidade ou, de forma mais ampla, a relação de
qualquer ciência com seus postulados epistemológicos (CERTEAU 2011,
p. 172, grifo do autor).

A longa citação não é despropositada. Ela explicita aquilo que me parece mais particular na abordagem de Certeau quanto à prática historiográfica como prática científica. Primeiro, é preciso que lembremos, mesmo que ao risco do cansaço, da particularidade do conceito de ciência do autor, sua atenção 
para a historicidade e para a diferença constitutiva da possibilidade de pensar em cada época. ${ }^{12} \mathrm{Em}$ seguida, convém notar que a figura do Outro, tão cara à sua concepção de história, deve muito à etnologia, mas principalmente à psicanálise de Freud e Lacan. Com efeito, retomá-la na teoria da história significa considerar que todo processo cognitivo parte de uma constituição particular da separação entre Mesmo e Outro; todo saber seria então construído sobre essa base identitária postulada e, depois, posta em questão. Essa crítica profunda ao recalque das condições de possibilidade do pensamento, sua naturalização, mais precisamente, é fundamento para esse conceito de história que estabelecerá na explicitação e no questionamento dessas condições sua possibilidade de saber, sua capacidade de construir um conhecimento ao mesmo tempo rigoroso, crítico e atento à própria historicidade. Sem oferecer saídas fáceis, Certeau cobra de nós que não tomemos a historicidade de nosso saber como um dado, mas sim como um problema.

Estamos, é claro, falando da formulação de um regime de historicidade localizável: não vem de longa data a possibilidade de pensar o presente como radicalmente histórico e dissociado de uma concepção progressista e teleológica (hegeliana, talvez) do tempo. Assim, convém sempre ter em mente a tensão que nos permite passar a experiência pela nossa grade fundamental do pensamento.

\section{A tensão da historicidade do pensamento}

A particularidade do texto que analiso aqui é a de que ele resulta de uma apresentação em um evento. As considerações complementares permitem então aprofundar determinados pontos da fala em relação a perguntas da audiência; não se poderia ignorá-las. Penso que o drama do pensável e do impensável - tema principal da fala de Certeau - atravessa também essas considerações complementares. Tomemos o primeiro ponto de atenção:

Atualmente, qualquer história é social. Compreender as condições de vida no século XVII [...] é estabelecer sua relação com a organização global da sociedade. Finalmente, é pensável apenas o que se refere a essa "razão" que é a organização de uma sociedade (CERTEAU 2011, p. 172).

Aqui Certeau toma de partida a nossa razão fundamental - ou um aspecto dela. Tratam-se das formas de referência absoluta a determinada dimensão da experiência: naquele período, o imperativo da história social; posteriormente, surgirá também a máxima "toda história é história cultural". Coloca então como problema o que nos é apresentado como dado. O social (ou o cultural) não é, a partir dessa perspectiva, uma característica que ontologicamente define uma organização ou um modo de viver na experiência; é, antes, um recorte produzido por uma racionalidade particular e determinada, uma tomada de posição que permite pensar a alteridade do passado ausente. Certeau reforça aqui a diferença inescapável desvelada por quem se debruça sobre esse Outro postulado. Ele continua: 
Ainda resta saber o que, atualmente, nos permite compreender. [...] Lucien Febvre diz-nos que, finalmente, as feiticeiras e os feiticeiros manifestamnos, também, algo do homem do século XVII, mas - acrescenta ele "no homem, acredito apenas no que é humano". Esta fórmula [...] supõe que Lucien Febvre sabe, por sua vez, o que do homem é crível ou o que é humano; ou, dito por outras palavras, ele dispõe de uma grade filosófica, de uma concepção de homem que lhe permite escolher, nas narrativas do século XVII, o que é "humano" ou não, o que é crível ou não. Pessoalmente, creio que esse tipo de divisão é problemático: nos é proibido, sem deixar de ser inevitável. Trata-se de um postulado que adotamos, uma posição que assumimos em relação a todo esse passado, para sermos capazes de pensá-lo (CERTEAU 2011, p. 173, grifo do autor).

"Proibido mas inevitável", o processo de apreensão da alteridade a partir de categorias presentes passa facilmente despercebido a quem é formado no interior de determinada tradição intelectual. Neste sentido, pode-se pensar o trabalho do intelectual como o trabalho de explicitar essas concepções naturalizadas: em particular o historiador, por seu trabalho privilegiado de investigação da alteridade, seria então responsável por lembrar o presente de sua historicidade. Não significa dizer que esse discurso é exclusividade dos intelectuais; como diz Terdiman, "Nossa compreensão da marginalidade deve integrar, tão profundamente quanto puder, o papel das bordas e das diferenças em criar as condições de possibilidade para qualquer compreensão" (TERDIMAN 2001, p. 404), ou seja, é preciso pensar nas capacidades criadoras do estabelecimento das diferenças. $E$, além disso, a relação dos homens com o tempo é muito mais ampla, como bem mostram autores como Koselleck e Hartog (KOSELLECK 2006; HARTOG 2011). Pode-se perceber as diferentes experiências temporais, por exemplo, através das políticas dedicadas à memória e ao patrimônio. Mas a relativização do presente em relação ao passado e o reconhecimento da alteridade para além da vulgata do progresso passa também pelo processo efetivo de reflexão sobre essa experiência temporal - e é aí que podemos encontrar uma das facetas de relevância social do trabalho historiográfico.

Se para Febvre estava claro aquilo que era efetivamente "humano" no homem, se para nós e nossos contemporâneos pode haver um determinado consenso sobre o que seja "cultura" - consenso, como sabemos, inexistente apontar para as significações singulares e históricas de cada categoria é tornar problemático, transformar em questão, aquilo que fundamenta todo o processo de pensamento de determinados grupos em determinadas épocas. É essencial seguir perguntando "Por quê?" e "Como?" para que não percamos de vista a provisoriedade de nosso pensamento e de nosso saber.

Certeau prossegue seu raciocínio elaborando uma crítica ao uso instrumental da psicanálise pela história:

Aliás, certo número de trabalhos, na área tanto da etnologia quanto da história, mostra que o uso os conceitos psicanalíticos torna-se uma espécie de retórica: é uma "maneira de falar". [...] Infelizmente, trata-se de conceitos vazios pelo fato de que, precisamente, seu único objeto consiste em designar ou cobrir pudicamente as regiões da história ainda incompreensíveis; eles circunscrevem o inexplicado, sem conseguirem explicá-lo; confessam sua ignorância (CERTEAU 2011, p. 174, grifo do autor). 
Trata-se de um uso bastante redutor segundo o qual o intelectual busca dar nome àquilo que não compreende a fim de mascarar a impossibilidade ou a falta de esforço de entender o fenômeno. Aos mistérios da fenomenologia da ação dos supostos sujeitos históricos, aos desvios inexplicáveis, o intelectual responde usando vulgarmente o "inconsciente" ou "a morte do pai" - ou outros conceitos emprestados sem rigor. ${ }^{13}$

Esse uso pobre e superficial não é exclusividade da psicanálise: no contexto de diálogos privilegiados com outras disciplinas, em especial as ciências sociais, é relativamente fácil encontrar exemplos de conceitos ou noções emprestados sem qualquer rigor para servir de designação daquilo que não se compreende algo como "usar um conceito que não entendo para designar um fenômeno que não entendo". O conceito de "representações sociais", emprestado da psicologia social, consiste em um desses exemplos (cf. CHARTIER 1990; GINZBURG 2001). ${ }^{14}$

\section{Um conceito eurocêntrico de história}

Em meio ao esforço de historicizar os fundamentos do nosso pensamento, Certeau questiona-se a respeito de sua concepção de história - mais particularmente se sua concepção não seria demasiado eurocêntrica. Concordando com o problema, ele diz: "Devemos, portanto, localizar, relativizar, finalmente, "historicizar" nossa concepção da história, pelo fato de que se constituem ou aparecem, atualmente, outras concepções culturais sobre a relação com o tempo" (CERTEAU 2011, p. 176). Quais as consequências dessa historicização? É preciso então pensar no processo cognitivo que é colocado em movimento pela história.

[...] por um lado, ela ocupa-se de um presente que pretende ser diferente; ela confirma uma inovação fundadora, um novo começo. Por outro, em um discurso, ela exprime a necessidade de situar-se em relação ao que, no presente, ainda dá testemunho de algo mais antigo, rebelde e resistente ao presente (CERTEAU 2011, p. 177).

Em que medida essa articulação se impõe com relação ao eurocentrismo de um determinado pensamento? Ora, aqui o esforço é o de encontrar um processo que, embora não universal, seja capaz de abarcar a historiografia profissional produzida em outras regiões. Pode-se objetar, justamente, que tal processo ainda se fundamenta na concepção europeia de erudição, de historiografia e de intelectualidade. Embora seja uma afirmação com a qual se possa concordar a princípio, precisamos nos dar um segundo momento para refletir: se por um lado essa concepção europeia de história serviu por muito tempo - e às vezes ainda serve - como instrumento de dominação cultural, de desprezo pelo Outro, de colonização e imperialismo, por outro lado a historiografia inspirada no pós-

\footnotetext{
13 Joan Scott recentemente colocou em questão o relacionamento entre psicanálise e historiografia, não apenas nos usos "teatrais", mas também nas tentativas efetivas de diálogo entre essas duas matrizes disciplinares. Ver SCOTT 2012.

${ }_{14}$ É interessante notar que o próprio Chartier mantém em tensão seu uso dos conceitos de "prática" e "representação", sempre buscando aprimorar sua aplicação conceitual. Tal atenção parece minoritária no conjunto de trabalhos que tomam emprestado o conceito de "representação".
} 
-colonialismo floresceu, e ainda floresce, nas antigas colônias. Tratou-se, com efeito, de fazer surgir uma historiografia que por muitas vezes questionou e denunciou os abusos europeus a partir dessa apropriação da forma de fazer a história.

José Carlos Reis, em um livro recente, lembra-nos de passagem do ceticismo europeu sobre a capacidade de compreensão de seus autores célebres pelos estrangeiros (REIS 2011). Mas mesmo à revelia dos mais conservadores, campos historiográficos mais ou menos independentes florescem em outras partes do mundo, apropriando-se daquilo que dizem pensadores europeus, e também pensadores locais, para produzir suas próprias narrativas. Rompe-se assim o monopólio do sentido caro a quem ainda deseja saber "exatamente o que se passou", mas incapaz de dar conta da significação plural a que um texto pode proporcionar: basta lembrarmos de $A$ invenção do cotidiano, obra na qual Certeau argumenta fortemente contra a ideia de uma "significação ortodoxa" ou do "sentido literal". Penso que esse movimento não pode ser desconsiderado, tratado como simples desvio. Em fidelidade crítica ao pensamento de Certeau, é preciso considerar essas apropriações como uma tomada de posição política e uma mudança nos termos da relação de poder entre a intelectualidade europeia e os pensadores "marginais". Em analogia à apropriação no cotidiano, penso que esse florescimento às margens da celebridade intelectual tão caras à França, Alemanha ou Inglaterra indica o fim, ou ao menos o enfraquecimento de um monopólio (ou de uma bipolaridade entre Europa e América do Norte) sobre o capital simbólico do pensamento.

210 Assim, retomando o processo delineado por Certeau para definir os procedimentos historiográficos, é preciso reconhecer essa dupla dimensão do mesmo: por um lado, fundado em um conceito determinado de história e de intelectualidade; por outro, apropriado e reconfigurado pelos centros nascentes e crescentes do pensamento pós-colonial em diversas partes do mundo.

Para finalizar a historicização do conceito de história, Certeau trata da questão inescapável do real e do papel do real na historiografia:

Outrora, o conceito de causalidade podia fornecer um respaldo ontológico ao discurso historiográfico; atualmente, através do que afirmamos até aqui a respeito da história, talvez seja possível aprofundar a via aberta por Dilthey: ele situava o real do lado de uma resistência encontrada pela investigação. [...] Talvez, também, deveria proceder-se a uma pesquisa, ainda mais aprofundada, das "condições de possibilidade" de qualquer história, considerando que o real é o irracionalizável que permite cada racionalização, em suma, o ausente que torna possível a história e the escapa (CERTEAU 2011, p. 178, grifo do autor).

Eis então em resumo toda a discussão elaborada ao longo do texto e a resposta, especulativa, é claro, ao problema levantado. Aqui, para Certeau, trata-se de pensar a capacidade de saber da história independentemente de um apoio ontológico: se não se pode apreender o real no discurso historiográfico, ao mesmo tempo é sempre em relação a esse ausente que se formula seu pensamento. O passado, o real, essa alteridade absoluta em relação ao qual se formula o texto do historiador permanecerá ausente; mas justamente pelo 
trabalho do historiador esse ausente é capaz de operar a partir e em direção dos fundamentos do pensamento. A partir porque é a partir de nossa concepção presente - o olhar sonhador que cria mundos que jamais conhecerá, citado no começo - que podemos nos debruçar sobre esse material que evoca a ausência; em direção a porque quando se apercebe da diferença o historiador é capaz de desnaturalizar o presente, relativizando-o em relação ao passado. Esse processo dialético constitutivo da e ao mesmo tempo constituído pela historiografia foi uma das grandes contribuições de Certeau à historiografia contemporânea. Se se pode dizer que tal concepção já está bastante difundida, respondo afirmando que essa fórmula, certamente parcial e histórica, apresenta-se como algo a ser lembrado constantemente - uma chamada de atenção importante. Trata-se, sim, de percebê-la também em sua historicidade: como foi formulada, em relação a quais problemas e com vistas a quais expectativas. Mas acima de tudo, é importante a manutenção de uma atitude crítica em relação aos postulados e aos fundamentos sobre os quais construímos nosso pensamento.

\section{Referências bibliográficas}

ANKERSMIT, F. A Escrita da História: a natureza da representação histórica. Londrina: EdUEL, 2012.

BeVERnAGE, B. Time, Presence, and Historical Injustice. History \& Theory, v. 47, n. 2, p. 149-167, 2008.

CARRARD, P. History as a Kind of Writing: Michel de Certeau and the poetics of historiography. The South Atlantic Quarterly, v. 100, n. 2, p. 465-482, 2001.

CERTEAU, M. A Escrita da História. $2^{a}$ ed. Rio de Janeiro: Forense Universitária, 2008.

. História e Psicanálise: entre ciência e ficção. Belo Horizonte: Autêntica, 2011.

CHARTIER, R. Writing the Practices. French Historical Studies, v. 21, n. 2, p. 255-264, 1998. 1990.

A História Cultural: entre práticas e representações. Lisboa: DIFEL,

GINZBURG, C. Olhos de Madeira: nove reflexões sobre a distância. São Paulo: Companhia das Letras, 2001.

HARTOG, F. Evidências em História: o que veem os historiadores. Belo Horizonte: Autêntica, 2011.

. Tempo e Patrimônio. Varia História, v. 22, n. 36, p. 261-273, 2006.

KOSELLECK, R. Futuro Passado: contribuições à semântica dos tempos históricos. Rio de Janeiro: Contraponto; PUC-RJ, 2006.

MARCOS, M. L. Identidade Narrativa e Ética do Reconhecimento. Études

Ricoeuriennes/Ricoeur Studies, v. 2, n. 2, p. 63-74, 2011. 
REIS, J. C. História da "Consciência Histórica" Ocidental Contemporânea: Hegel, Nietzsche, Ricoeur. Belo Horizonte: Autêntica, 2011.

REVEL, J. História e Historiografia: exercícios críticos. Curitiba: Editora UFPR, 2010.

RICOEUR, P. Tempo e Narrativa: 1. A intriga e a narrativa histórica. São Paulo: WMF Martins Fontes, 2010.

A Memória, a História, o Esquecimento. Campinas: Editora Unicamp, 2007.

RÜSEN, J. How to overcome ethnocentrism: approaches to a culture of recognition by history in the twenty-first century. History \& Theory, v. 43, n. 4, p. 118-129, 2004.

. The horror of ethnocentrism: westernization, cultural difference, and strife in understanding non-western pasts in historical studies. History \& Theory, v. 47, n. 2, p. 261-269, 2008.

$\mathrm{SCOTT}, \mathrm{J}$. The incommensurability of psychoanalysis and history. History \& Theory, v. 51, n. 1, p. 63-83, 2012.

TERDIMAN, R. The Marginality of Michel de Certeau. The South Atlantic Quarterly, v. 100, n. 2, p. 399-421, 2001.

. The Response of the Other. Diacritics, v. 22, n. 2, p. 2-10, 1992.

212 WANDEL, T. Michel de Certeau's Place in History. Rethinking History, v. 4, n. 1 , p. 55-76, 2000.

WEYMANS, W. Michel de Certeau and the Limits of Historical Representation. History \& Theory, v. 43, n. 2, p. 161-178, 2004. 